\title{
Germinação assimbiótica e desenvolvimento de Dendrobium nobile Lindl. sob efeito de reguladores vegetais no tratamento pré-germinativo
}

\author{
SOARES, J.S. ${ }^{1 *}$; ROSA, Y.B.C.J. ${ }^{1}$; SUZUKI, R.M. ${ }^{2}$; SCALON, S.P.Q. ${ }^{1}$ ROSA JUNIOR, E.J. ${ }^{1}$ \\ ${ }^{1}$ Faculdade de Ciências Agrárias - FCA/UFGD, Rodovia Dourados-Itahum, km 12, Caixa Postal 533, CEP: 79804- \\ 970, Dourados-Brasil *jacke.schultz@gmail.com ${ }^{2}$ Instituto de Botânica de São Paulo, IBOT/SP, Caixa Postal \\ 3005, CEP: 01061-970, São Paulo-Brasil
}

\begin{abstract}
RESUMO: O presente trabalho teve como objetivo estudar a influência dos reguladores vegetais $\mathrm{BAP}$ e $\mathrm{GA}_{3}$ como tratamentos pré-germinativos no processo de germinação e desenvolvimento inicial de plântulas de Dendrobium nobile, espécie importante pelas propriedades farmacológicas como anti-oxidante, vasodilatadora e até mesmo anti-cancerígena, além do valor ornamental. Os tratamentos pré-germinativos consistiram de $\mathrm{BAP}$ e $\mathrm{GA}_{3}$, separadamente, nas concentrações de 0,$0 ; 1,0 ; 2,0$ e 5,0 $\mathrm{mg} \mathrm{L}^{-1}$. Após seis meses da semeadura in vitro e manutenção em câmara de germinação e de crescimento com temperatura e foto-período controlados ( 12 horas e $23^{\circ} \mathrm{C} \pm 2$ ), foram avaliados os parâmetros número de sementes germinadas, porcentagem de germinação, massa fresca e altura das plântulas, diâmetro e número de pseudobulbos, número de folhas, número de raízes, e o comprimento da maior raiz. O delineamento experimental foi inteiramente casualizado. Todas as variáveis foram submetidas à análise de variância e de regressão, quando significativas. As sementes de $D$. nobile germinaram melhor na ausência de reguladores vegetais e os tratamentos com BAP ou $\mathrm{GA}_{3}$ na embebição das sementes pouco beneficiaram o desenvolvimento in vitro de $D$. nobile.
\end{abstract}

Palavras-chave: Orchidaceae, olho de boneca, cultivo in vitro, BAP, $\mathrm{GA}_{3}$

ABSTRACT: Asymbiotic germination and development of Dendrobium nobile Lindl. under the effect of plant growth regulators in pre-germinative treatment. The present study aimed to investigate the influence of plant growth regulators BAP and $\mathrm{GA}_{3}$ as pre-germinative treatment in the process of germination and initial development of seedlings of Dendrobium nobile, a species important for its pharmacological properties like antioxidant, vasodilator and even anticancer, besides its ornamental value. Pre-germinative treatments consisted of BAP and $\mathrm{GA}_{3}$, separately, at the concentrations of $0.0 ; 1.0 ; 2.0$ and $5.0 \mathrm{mg} \mathrm{L}^{-1}$. At six months after in vitro sowing and maintenance in a germination and growth chamber with controlled temperature and photoperiod $\left(12\right.$ hours and $23^{\circ} \mathrm{C} \pm 2$ ), the following parameters were evaluated: number of germinated seeds, percentage of germination, fresh mass and height of seedlings, number and diameter of pseudo-bulbs, number of leaves, number of roots, and length of the largest root. The experimental design was completely randomized. All variables underwent analysis of variance and regression analysis when significant. $D$. nobile seeds presented better germination in the absence of plant growth regulators and the treatments with BAP or $\mathrm{GA}_{3}$ in seed imbibition little benefited $D$. nobile in vitro development.

Key words: Orchidaceae, olho-de-boneca, in vitro cultivation, $\mathrm{BAP}, \mathrm{GA}_{3}$

\section{INTRODUÇÃO}

A família Orchidaceae originou-se na Malásia, durante o período cretáceo, quando em sua maioria as famílias das angiospermas tornaram-se diferenciadas (Garay, 1972). Tal família está mais bem representada nas regiões tropicais e subtropicais (Stoutamire, 1964), podendo crescer como epífitas sobre árvores e arbustos, ser rupículas, terrícolas ou saprófitas.

Dendrobium é o segundo maior gênero da família e possui várias espécies com propriedades medicinais (Zhang et al., 2005). A espécie Dendrobium nobile Lindl, conhecida como olho de

Recebido para publicação em 19/10/2010

Aceito para publicação em 18/05/2012

Rev. Bras. Pl. Med., Botucatu, v.14, n.4, p.617-623, 2012. 
boneca, é uma orquídea herbácea, epífita, perene e entouceirada, originária da China e Himalaia, usada na medicina tradicional chinesa e japonesa (Lorenzi \& Souza, 1999).

Há relatos de que as plantas de $D$. nobile possuem várias propriedades farmacológicas, incluindo anti-oxidantes, vasodilatadoras e até mesmo anti-cancerígenas (Lin et al., 2003). Os chineses a utilizam para diversas finalidades na medicina popular (Miller, 1978). Wang et al. (1985) isolaram os alcalóides dendrobina e 3-hidroxi 2-oxodendrobina dos pseudobulbos, identificando-os como substâncias que são utilizadas na China para aumentar o apetite, estimularem a secreção da saliva e melhorar a saúde em geral.

Estudos sobre o processo de propagação dessa orquídea são extremamente importantes, não apenas para que se possa melhorar a produção, mas também para preservá-las, evitando a extinção. Neste sentido, o cultivo in vitro é comprovadamente eficiente no aumento da germinação de sementes de várias espécies desta família, além de produzir plantas com excelente qualidade fitossanitária.

Orchidaceae diferencia-se da maioria das famílias botânicas pelas sementes não possuírem reservas nutritivas suficientes para promover a germinação (Ramos, 1969). Desta forma, na natureza, as sementes germinam em simbiose com fungos micorrízicos (Arditti, 1979). Entretanto, a utilização de meios de cultura no cultivo in vitro torna possível a germinação das sementes e o desenvolvimento de plântulas de orquídeas assimbioticamente.

Os reguladores vegetais podem ser produzidos também por fungos micorrízicos. Assim, é possível postular que essas substâncias podem ser fornecidas pelos fungos durante a germinação simbiótica de sementes de orquídeas (Miyoshi \& Mii, 1995).

As giberelinas estimulam a germinação de sementes não dormentes, além de favorecer a quebra da dormência das mesmas. Esse hormônio vegetal promove a germinação, dentre outros efeitos fisiológicos, atuando como mediador entre fatores ambientais e fatores internos restritivos da germinação; pode induzir genes que codificam enzimas que reduzem a resistência mecânica dos envoltórios da semente ou ter efeito direto sobre o potencial de crescimento do embrião (Kerbauy, 2008).

No entanto, há outros reguladores vegetais envolvidos no processo da germinação, como as citocininas, que têm a capacidade de promover a germinação em algumas espécies, porém os efeitos destas nesse processo ainda são pouco conhecidos (Kerbauy, 2008) e, em orquídeas, informações sobre a capacidade das citocininas promoverem a germinação são escassas.

As variações genéticas dentro da família Orchidaceae podem resultar em respostas diferentes ao uso de reguladores vegetais. Assim torna-se importante investigar a atuação dos diferentes hormônios vegetais na espécie que se trabalha. Diante do exposto, o presente trabalho teve como objetivo estudar a influência da embebição das sementes com BAP (6-benzilaminopurina) e $\mathrm{GA}_{3}$ (ácido giberélico) no processo de germinação e desenvolvimento inicial de plântulas de $D$. nobile in vitro.

\section{MATERIALE MÉTODO}

O experimento foi realizado no Laboratório de cultivo in vitro da Faculdade de Ciências Agrárias (FCA) da Universidade Federal da Grande Dourados (UFGD), em Dourados-MS. Foram utilizadas como material de estudo sementes de $D$. nobile produzidas por meio de autopolinização manual, cedidas pelo Orquidário da FCA, da Universidade Federal da Grande Dourados - UFGD.

Cápsulas maduras da espécie foram abertas com o uso de estilete e as sementes retiradas, homogeneizadas, pesadas e $5 \mathrm{mg}$ delas foram submetidas ao teste de tetrazólio que resultou em 800 sementes viáveis pormg de sementes. Após a confirmação da viabilidade procedeu-se aos tratamentos prégerminativos com 6-benzilaminopurina (BAP) e ácido giberélico $\left(\mathrm{GA}_{3}\right)$, ambos nas concentrações de 0,$0 ; 1,0$; 2,0 e $5,0 \mathrm{mg} \mathrm{L}^{-1}$.

Foram utilizados, tanto para BAP quanto para $\mathrm{GA}_{3}, 10 \mathrm{~mL}$ de cada concentração das soluções de reguladores vegetais para a embebição de porções de $10 \mathrm{mg}$ de sementes. Durante a embebição as oito suspensões de sementes foram armazenadas em ambiente desprovido de luz. Decorridas 24 horas as sementes foram lavadas com $50 \mathrm{~mL}$ de água destilada por três vezes mediante a utilização de papel filtro.

Cada porção de $10 \mathrm{mg}$ de sementes foi transferida para Erlenmeyer, com auxílio de espátula e desinfestada por 15 minutos com solução composta por $3 \mathrm{~mL}$ de hipoclorito de sódio $(2,5 \%)$ e $6 \mathrm{~mL}$ de água destilada esterilizada em autoclave (Campos, 2002). Decorrido este tempo a suspensão foi diluída para $50 \mathrm{~mL}$ com água destilada esterilizada em autoclave, no interior da câmara de fluxo laminar vertical, para realização do semeio in vitro.

O meio de cultura utilizado para semeio foi o de Campos (2002) modificado pela substituição do adubo Dyna Gro por NPK e pela quantificação dos ingredientes, sendo composto por $70 \mathrm{~g} \mathrm{~L}^{-1}$ de tomate maduro sem casca e sementes, $150 \mathrm{~mL} \mathrm{~L}^{-1}$ de água de coco verde, $50 \mathrm{~g} \mathrm{~L}^{-1}$ de banana nanica madura sem casca, $3 \mathrm{~mL} \mathrm{~L}^{-1}$ de NPK 10-10-10, $17 \mathrm{~g} \mathrm{~L}^{-1}$ de ágar bacteriológico, $25 \mathrm{~g} \mathrm{~L}^{-1}$ de açúcar cristal e $3 \mathrm{~g} \mathrm{~L}^{-1} \mathrm{de}$ carvão ativado. Após homogeneização no liquidificador, o $\mathrm{pH}$ foi ajustado para $5,0 \mathrm{com} \mathrm{KOH}$ e $80 \mathrm{~mL}$ do meio de cultura foram transferidos para frascos de $600 \mathrm{~mL}$ providos de tampa metálica, sendo esterilizados em autoclave por $20 \mathrm{~min}$ a $121^{\circ} \mathrm{C}$ e $1 \mathrm{~atm}$ de pressão.

Rev. Bras. Pl. Med., Botucatu, v.14, n.4, p.617-623, 2012. 
Solidificado o meio, os frascos foram transportados para câmara de fluxo laminar, previamente esterilizada por 30 minutos com luz germicida, para realização do semeio in vitro. Em cada frasco foram inoculados, por meio de pipetador automático, $2 \mathrm{~mL}$ da suspensão de sementes que continham cerca de 320 sementes viáveis. Foram utilizados três frascos por tratamento.

Após o semeio, os frascos foram tampados e vedados com filme plástico, acondicionados em câmara de germinação e crescimento e mantidos por seis meses a $23 \pm 2^{\circ} \mathrm{C}$ sob fotoperíodo de 12 horas com $28 \mu \mathrm{mol} \mathrm{m}{ }^{-2} \mathrm{~s}^{-1}$ de irradiância, provenientes de lâmpadas brancas fluorescentes (40W).

Decorridos seis meses do semeio, os frascos foram abertos e as plântulas foram lavadas em água corrente até total remoção do substrato. $A$ seguir foram contados o número de plântulas e o número de protocormos. Para o cálculo da porcentagem de germinação foram considerados os protocormos e as plântulas. Para o número de plântulas foram consideradas apenas as plântulas que apresentassem sistema radicular e parte aérea identificáveis a olho nu.

A porcentagem de germinação foi calculada considerando-se o número médio de sementes viáveis identificadas pelo teste tetrazólio que foram inoculadas em cada frasco de cultivo.

As plântulas foram classificadas quanto à altura, sendo selecionadas as 26 plântulas mais representativas de cada tratamento para a avaliação dos atributos vegetais. Cada plântula foi avaliada quanto à massa fresca $(\mathrm{g})$, altura $(\mathrm{cm})$, diâmetro $(\mathrm{cm})$ e número de pseudobulbos, número de folhas, número de raízes e comprimento da maior raiz $(\mathrm{cm})$.

Foi utilizado o delineamento experimental inteiramente casualizado e cada regulador vegetal foi avaliado separadamente. Para a análise da porcentagem de germinação e número de plântulas utilizou-se quatro tratamentos, concentrações de reguladores vegetais $\left(0,0 ; 1,0 ; 2,0\right.$ e $\left.5,0 \mathrm{mg} \mathrm{L}^{-1}\right)$ com três repetições e para os atributos vegetais quatro tratamentos, concentrações de reguladores vegetais $\left(0,0 ; 1,0 ; 2,0\right.$ e $\left.5,0 \mathrm{mg} \mathrm{L}^{-1}\right)$ com 26 repetições.

Todos os parâmetros e atributos vegetais foram submetidos à análise de variância e quando significativos à regressão (Banzato \& Kronka, 1992) com a utilização do aplicativo computacional SISVAR (Ferreira, 2003).

\section{RESULTADO E DISCUSSÃO}

\section{Germinação e número de plântulas}

A germinação das sementes foi observada 18 dias após o semeio, quando houve produção de clorofila pelos protocormos. Tanto a utilização de BAP quanto de $\mathrm{GA}_{3}$ na embebição das sementes de $D$. nobile afetou significativamente $(p<0,01)$ a porcentagem de germinação e número de plantas, sendo os maiores resultados observados na ausência dos reguladores vegetais (Figura 1).

A concentração de $3,31 \mathrm{mg} \mathrm{L}^{-1}$ de BAP, obtida pela regressão, propiciou os menores números de plântulas $(5,36)$ e as menores taxas de germinação $(1,68 \%)$, enquanto a ausência do regulador propiciou 148,29 plântulas com taxa de germinação de 46,47\% (Figuras 1A e 1B).

As sementes de $D$. nobile germinaram mais na ausência de BAP do que nos tratamentos prégerminativos com esta citocinina. Resultados semelhantes foram observados por Miyoshi \& Mii (1995) em Calanthe discolor, onde as maiores concentrações de BAP na embebição inibiram a germinação das sementes. Entretanto, Pedroza et al. (2005) relatam que a adição de $3,37 \mathrm{mg} \mathrm{L}^{-1}$ de $\mathrm{BAP}$, combinada ou não com auxina e $\mathrm{GA}_{3}$ em meio de cultura, promoveu a porcentagem máxima de germinação de sementes de Comparettia falcata, indicando que além da concentração, a forma de utilização desses reguladores vegetais podem favorecer ou não a germinação de Orchidaceae.

Os resultados desse trabalho podem indicar que $D$. nobile possui adequado nível endógeno de citocininas as quais são responsáveis pela mobilização das gotículas de lipídeos que, segundo Manning \& Van Staden (1987), são as únicas substâncias de reserva contidas no embrião dessas plantas disponíveis para os processos metabólicos envolvidos na germinação das orquídeas.

De maneira análoga ao BAP, a ausência de $\mathrm{GA}_{3}$ na embebição de sementes proporcionou o maior número de plântulas $(145,91)$ e a maior porcentagem de germinação (49,47\%). Os menores resultados para essas variáveis foram observados quando utilizada a concentração de $2,99 \mathrm{mg} \mathrm{L}^{-1}$ de $\mathrm{GA}_{3}$ que proporcionou 25,59 plântulas e taxa de germinação de $9,06 \%$ (Figuras 1C e 1D).

Contrapondo-se aos resultados deste trabalho, Santos et al. (2007) verificaram que a utilização de $1 \mathrm{mg} \mathrm{L}^{-1}$ de $\mathrm{GA}_{3}$ na embebição de sementes de Cattleya bicolor proporcionou o maior número de plântulas; entretanto, concentrações entre 0 e $5 \mathrm{mg} \mathrm{L}^{-1}$ de $\mathrm{GA}_{3}$ não propiciaram diferenças significativas na porcentagem de germinação. Miyoshi \& Mii (1995) não observaram efeitos significativos sobre a germinação de sementes e formação de protocormos de Calanthe discolor com a utilização das doses 10 e $100 \mathrm{mg} \mathrm{L}^{-1}$ de $\mathrm{GA}_{3}$ em embebição das sementes por 24 horas. Esses resultados indicam que o balanço de reguladores vegetais aplicados exogenamente é peculiar para cada espécie.

Os resultados observados nesse trabalho são concordes com o relatado por Arditti \& Ernst (1984), 

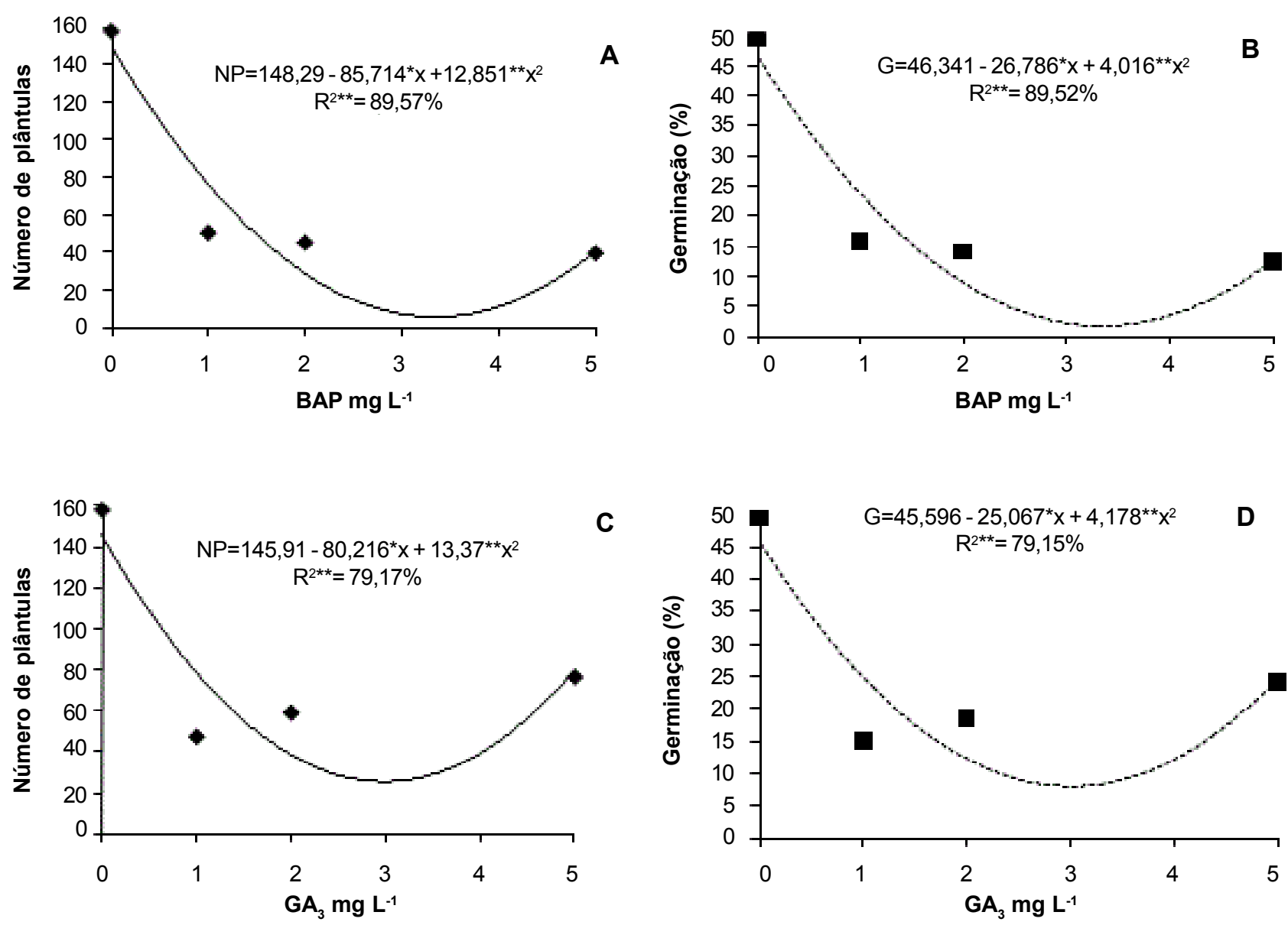

FIGURA 1. Valores estimados de número de plantas e porcentagem de germinação de plantas de $D$. nobile, em função das concentrações de reguladores vegetais utilizados.

que atribuíram aos fornecimentos exógenos de giberelinas a inibição dos processos germinativos em Orchidaceae e corroboram com os resultados de Miyoshi \& Mii (1995), que acrescentaram que sementes de Calanthe discolor podem ser muito sensíveis ao $\mathrm{GA}_{3}$ na fase inicial de germinação, uma vez que o processo inibitório foi detectado com exposição ao fitorregulador por período de 24 horas.

Embora a utilização de $\mathrm{GA}_{3}$ em tratamentos pré-germinativos tenha sido inibitória para algumas Orchidaceae, Gil-Martínez (1995) afirma que, em condições naturais, as sementes dessa família podem precisar de $\mathrm{GA}_{3}$ fornecido pelo fungo micorrízico, a fim de iniciar o processo germinativo. Esta é possivelmente a razão pela qual $\mathrm{GA}_{3}$ adicionado em meios assimbióticos (que substituem as associações micorrízicas) tem sido importante, conforme relato de Pedroza et al. (2005), para a germinação de Comparettia falcata.

As giberelinas são relatadas como benéficas à quebra de dormência embrionária (Grattapaglia \& Machado, 1998; Jesus et al., 2003) ou tegumentar de muitas espécies vegetais (Kerbauy, 2008), entretanto, os resultados observados neste trabalho constataram o efeito inibitório e não estimulador de $\mathrm{GA}_{3}$ na germinação de $D$. nobile.

\section{Atributos vegetais}

Os tratamentos pré-germinativos com BAP foram estatisticamente significativos $(p<0,01)$ para todos os atributos vegetais estudados, exceto diâmetro de pseudobulbos cujo valor médio foi de 0,51 cm plântula-1 independentemente da concentração estudada.

Conforme é possível observar na Figura 2, o número de folhas foi influenciado pelas concentrações de citocinina, apresentando comportamento quadrático, sendo os maiores valores (5,47 plântula-1 $)$ observados com a utilização de 2,7 mg L-1 de BAP. Na concentração $2,8 \mathrm{mg} \mathrm{L}^{-1}$ foram observados os maiores números de pseudobulbos (2,35 plântula $\left.{ }^{-1}\right)$ que também apresentaram comportamento quadrático. O número de pseudobulbos por planta é de extrema importância, 


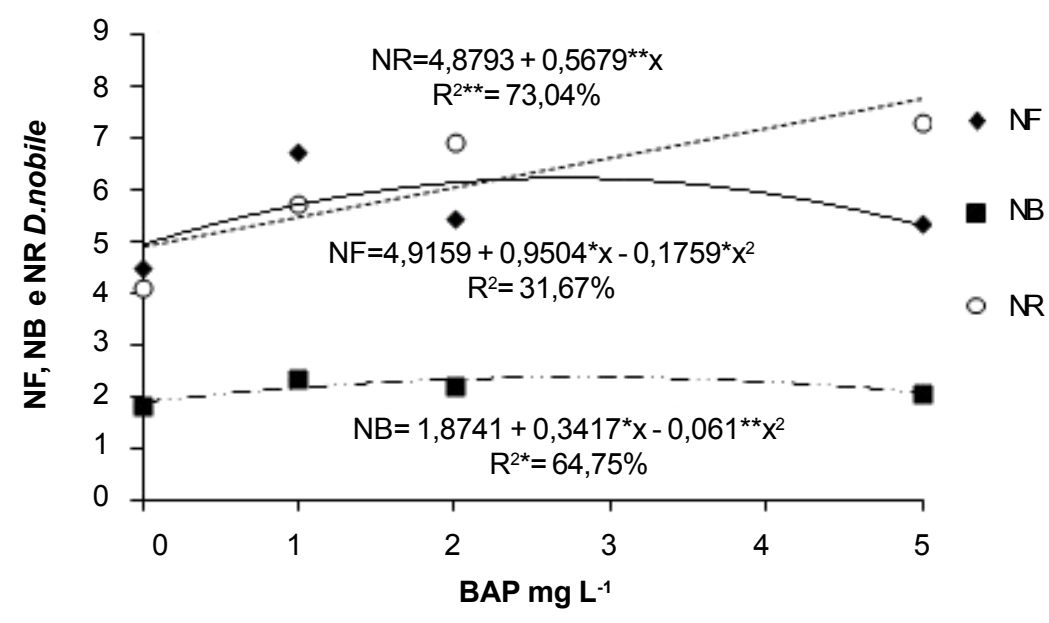

FIGURA 2. Valores estimados de número de folhas (NF), número de pseudobulbos (NB) e número de raízes (NR) de plantas de $D$. nobile, em função das concentrações de BAP utilizadas.

já que desse órgão são extraídos os compostos com propriedades medicinais.

O aumento da concentração de BAP proporcionou maior formação de raízes e os maiores números $\left(7,7\right.$ raízes plântula $\left.{ }^{-1}\right)$ foram obtidos na concentração $5 \mathrm{mg} \mathrm{L}^{-1}$ (Figura 2). Como verificado na Figura 3 a concentração $3,18 \mathrm{mg} \mathrm{L}^{-1}$ de BAP proporcionou os maiores valores de comprimento da maior raiz $(6,09 \mathrm{~cm})$ e, de acordo com Silva (2003) aumentar o comprimento das raízes é uma maneira da plântula buscar os nutrientes necessários ao desenvolvimento. A partir daí houve decréscimo dessa variável, indicando que as reservas foram provavelmente direcionadas para outras partes da planta.

As maiores alturas de planta $(2,75 \mathrm{~cm})$ foram registradas na concentração $2,5 \mathrm{mg} \mathrm{L}^{-1}$ (Figura 3 ) e a maior massa fresca de pseudobulbos $(1,11 \mathrm{~g})$ foi propiciada pela concentração de $3,1 \mathrm{mg} \mathrm{L}^{-1}$ (Figura 3). Como o peso da massa fresca da plântula é uma referência de vigor, poder-se-ia estabelecer que a concentração de $2,5 \mathrm{mg} \mathrm{L}^{-1}$ de BAP é a mais indicada para a embebição de sementes de $D$. nobile. Para Zaerr \& Mapes (1985), o BAP é a citocinina mais potente e menos dispendiosa para promover o desenvolvimento da parte aérea da plântula.

A embebição de sementes com $\mathrm{GA}_{3}$ foi estatisticamente significativa para todos os atributos vegetais estudados exceto diâmetro de pseudobulbos, o qual apresentou valor médio de $0,49 \mathrm{~cm}$ independentemente da concentração estudada. Para esse regulador vegetal a concentração de $2,9 \mathrm{mg} \mathrm{L}^{-1}$ propiciou os maiores números de folhas (7,99 plântula $\left.^{-1}\right)$



$\square \mathrm{CR}$



- MF

FIGURA 3. Valores estimados de comprimento da maior raiz (CR), altura da planta (AP) e massa fresca das plantas (MF) de $D$. nobile, em função das concentrações de BAP utilizadas. 
e na concentração $3,2 \mathrm{mg} \mathrm{L}^{-1}$ foram observados os maiores números de pseudobulbos (2,54 plântula $\left.^{-1}\right)$ (Figura 4).

Hew \& Clifford (1993) relatam que o uso de giberelinas no desenvolvimento de plântulas de orquídeas tem consequência negativa levando à clorose e menor número de folhas, embora com maior comprimento, podendo também afetar o surgimento do sistema radicular, indicando que durante a germinação, as sementes sintetizam a quantidade necessária de giberelinas, de modo que qualquer adição altera a concentração supraótima anteriormente existente. Entretanto, os resultados observados no presente trabalho indicam que aplicações de $\mathrm{GA}_{3}$ entre 2 e $3 \mathrm{mg} \mathrm{L}^{-1} \mathrm{em}$ tratamentos pré-germinativos são favoráveis, em $D$. nobile, aos parâmetros citados.
Para número de raízes, os maiores valores (5,83 raízes plântula-1 ${ }^{-1}$ foram obtidos na concentração $3,3 \mathrm{mg} \mathrm{L}^{-1}$ de GA $\mathrm{G}_{3}$ (Figura 4). As concentrações de giberelina (Figura 5) também promoveram influência positiva no comprimento da maior raiz, onde a maior concentração utilizada $\left(5 \mathrm{mg} \mathrm{L}^{-1}\right)$, propiciou os maiores valores $(5,80 \mathrm{~cm})$. Esses dados corroboram com informações de Salisbury \& Ross (1992) que relatam que a giberelina pode favorecer o desenvolvimento radicular.

As maiores alturas de planta $(2,55 \mathrm{~cm})$ foram encontradas na concentração de $2,8 \mathrm{mg} \mathrm{L}^{-1}$ (Figura $5)$ e a maior massa fresca $(0,825 \mathrm{~g})$ foi propiciada pela concentração de $3,5 \mathrm{mg} \mathrm{L}^{-1}$ de $\mathrm{GA}_{3}$ (Figura 5). Concentrações maiores de giberelina inibiram o ganho de peso das plântulas.

O efeito estimulatório da giberelina observado

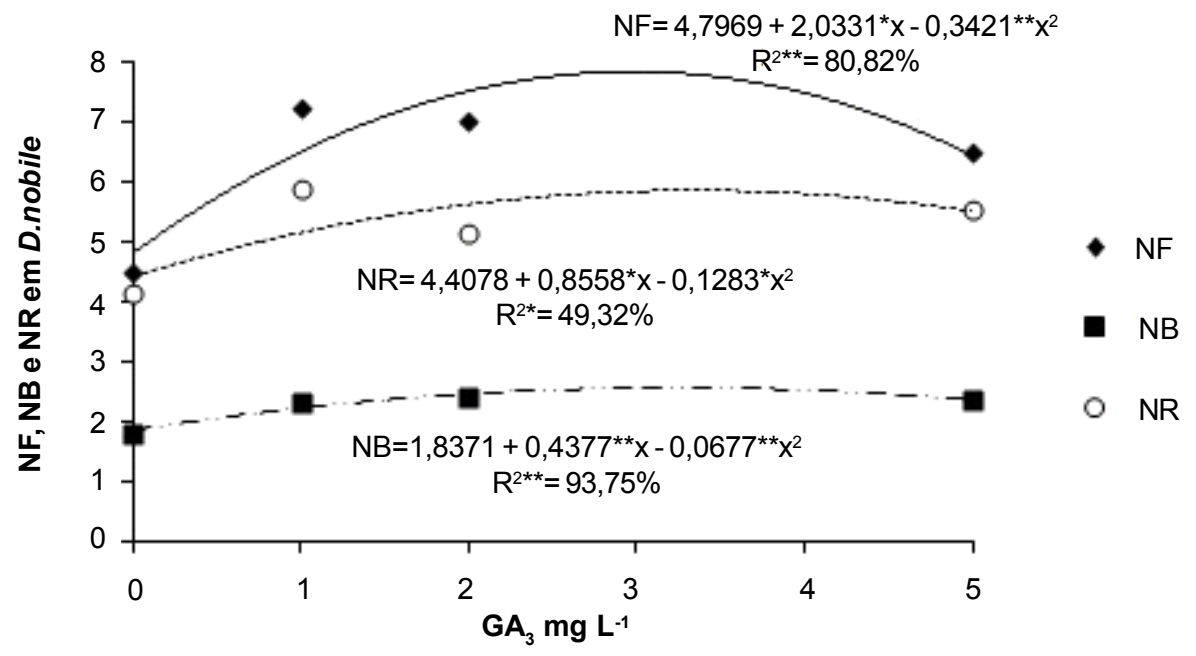

FIGURA 4. Valores estimados de número de folhas (NF), número de pseudobulbos (NB) e número de raízes (NR) de plantas de $D$. nobile, em função das concentrações de $\mathrm{GA}_{3}$ utilizadas.
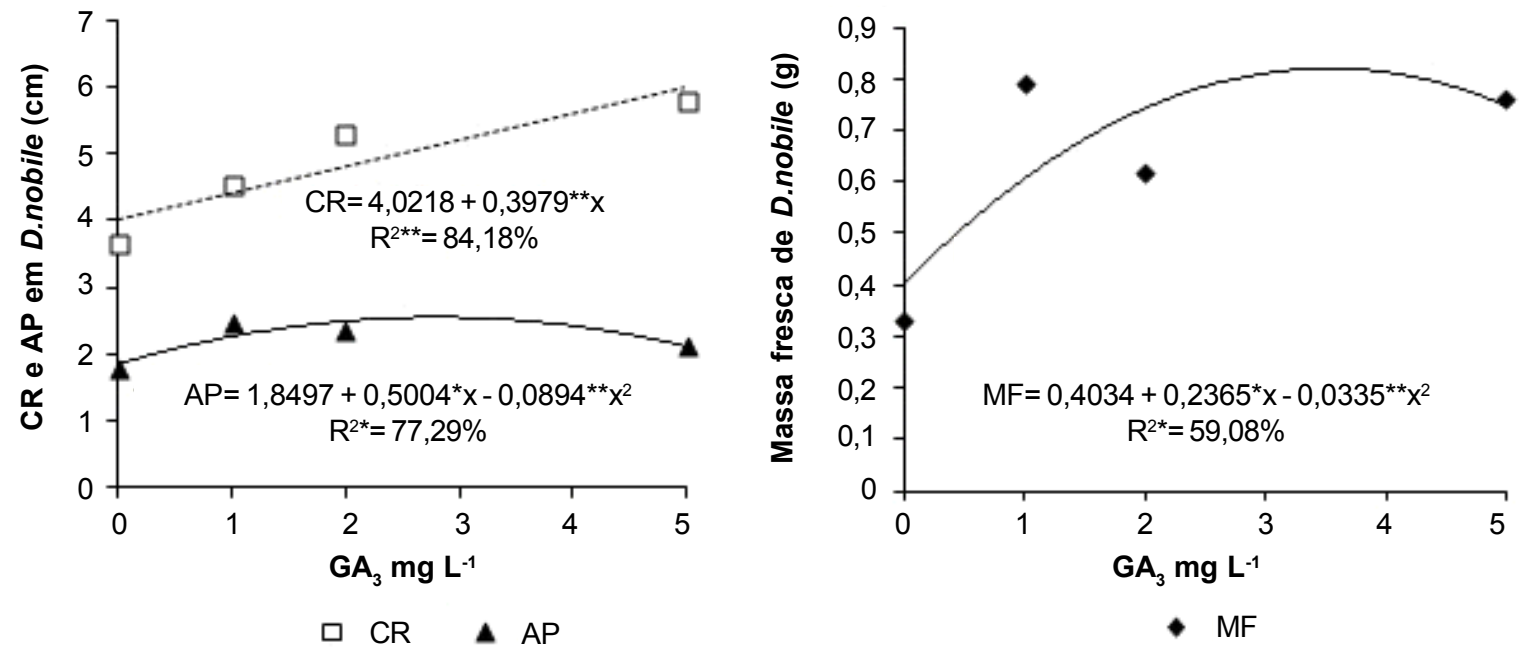

FIGURA 5. Valores estimados de comprimento da maior raiz (CR), altura da planta (AP) e massa fresca das plantas (MF) de $D$. nobile, em função das concentrações de $\mathrm{GA}_{3}$ utilizadas. 
na altura da planta, provavelmente, deveu-se ao fato de que, nos vegetais, esse regulador participa de muitas atividades fisiológicas importantes, como o estímulo à expansão longitudinal das células, tendo efeito no crescimento, especialmente no alongamento caulinar (Kerbauy, 2008).

A baixa exigência de ácido giberélico verificada para estas variáveis pode ser explicada pelo fato dos embriões possuírem capacidade de produzir certa quantidade deste fitohormônio, como foi verificado por Jimenez et al. (2001).

\section{CONCLUSÃO}

Os resultados observados neste trabalho mostraram que, mesmo tendo inibido a germinação de sementes e proporcionado menores números de plântulas, o tratamento pré-germinativo com $2 \mathrm{mg} \mathrm{L}^{-1}$ de BAP ou $\mathrm{GA}_{3}$ na embebição das sementes beneficiou, posteriormente, o desenvolvimento in vitro de $D$. nobile, colaborando inclusive com o aumento do número de pseudobulbos por planta, essencial para o isolamento dos componentes medicinais.

\section{REFERÊNCIA}

ARDITTI, J. Aspects of the physiology of orchids. Advances in Botanical Research, v.7, p.421-655, 1979.

ARDITTI, J.; ERNST, R. Physiology of germinating orchid seeds. In: ARDITTI, J. (Ed.). Orchid biology, reviews and perspectives. New York : Cornell University Press, 1984. p.170-222.

BANZATO, D.A.; KRONKA, S.N. Experimentação agrícola. 2.ed. Jaboticabal: FUNEP, 1992. 247p.

CAMPOS, D.M. Orquídeas: manual prático da cultura. 3.ed. Rio de Janeiro: Expressão e Cultura, 2002. 143p.

FERREIRA, D.F. Programa de análises estatísticas (Statistical Analysis Software) e planejamento de Experimentos - SISVAR. Universidade Federal de Lavras. 2003.

GARAY, L.A. On the origin of the Orchidaceae II. Journal of the Arnold Arboretum, v.53, p.202-15, 1972.

GIL-MARTÍNEZ, F. Elementos de fisiología vegetal. España: Mundi-Prensa, 1995. 1147p.

GRATTAPAGLIA, D.; MACHADO, M.A. Micropropagação. In: TORRES, A.C.; CALDAS, L.S.; BUSO, J.A. Cultura de tecidos e transformação genética de plantas. Brasília: EmbrapaCNPH, 1998. p.183-260.

HEW, C.S.; CLIFFORD, P.E. Plant growth regulators and the orchid cut-flower industry. Plant Growth Regulation, v.13, p.231-9, 1993.
JIMENEZ, V.M.; GUEVARA, E.; BANGERTH, F. Endogenous hormone levels in habituated nucellar Citrus callus during the initial stages of regeneration. Plant Cell Reports, v.20, n.1, p.92-100, 2001.

JESUS, A.M.S. et al. Cultivo in vitro de embriões zigoticos de Jatropha. Revista Ceres, v.50, n.288, p.183-9, 2003.

KERBAUY, G.B. Fisiologia vegetal. 2.ed. Rio de Janeiro: Guanabara Koogan S.A., 2008. 431p.

LIN, P. et al. Advances in studies on pharmacology of plants from Dendrobium Sw. Chinese Traditional and Herbal Drugs, v.34, p.19-22, 2003.

LORENZI, L.; SOUZA, H.M. Plantas ornamentais do Brasil: arbustivas, herbáceas e trepadeiras. 2.ed. Nova Odessa: Instituto Plantarum, 1999. 1088p.

MANNING, J.C.; VAN STADEN, J. The development and mobilization of seed reserves in some African orchids. Australian Journal of Botany, v.35 p.343-53, 1987.

MILLER, M.A. Orchids of economic use. American Orchid Society Bulletin, v.47, p.512-21, 1978.

MIYOSHI, K.; MII, M. Phytohormone pré- treatment for the enhancement of seed germination and protocorm formation by the terrestrial orchid, Calanthe discolor (Orchidaceae), in asymbiotic culture. Scientia Horticulturae, v.63, n.3-4, p.263-7, 1995.

PEDROZA, J.; FERNÁNDEZ, C.; SUÁREZ, A. Evaluation of the effect of three growth regulators in the germination of Comparettia falcata seeds under in vitro conditions. In Vitro Cellular \& Developmental Biology Plant, v.41, p.838-43, 2005.

RAMOS, M.S.S. A orquídea e sua reprodução por semente. São Paulo: Ed. Saraiva, 1969. 163p.

SALISBURY, F.B.; ROSS, C.W. Plant physiology. 4.ed. California: Wadsworth, 1992. 682p.

SANTOS, G.A. et al. Utilização de reguladores hormonais na germinação e formação de plântulas in vitro de orquídeas. Cesumar, v.9, n.1, p.7-12, 2007.

SILVA, E.F. Multiplicação e crescimento in vitro de orquídea Brassocattleya Pastoral x Laeliocattleya Amber Glow. 2003. 62p. Dissertação (Mestrado em Fitotecnia) Universidade Federal de Lavras. Lavras.

STOUTAMIRE, W.P. Seeds and seedling of native orchids. Michigan Botanist, v.3, n.4, p.104-19, 1964.

WANG, X.C.K.; TONFAG, Z.H.A.O; HNGCTAO, C.H.E. Dendrobine and 3-hydryoxy-2- oxodendrobine from Dendrobium nobile. Journal of Natural Products, v.48, n.5, p.786-801, 1985.

ZAER J.B.; MAPES M.O. Action of growth regulators. In: BONGA, J.M.; DURZAN, D.J. (Eds). Tissue culture in forestry. Dordrecht: Martinus Nijhoff Publishers, 1985. p.231-55.

ZHANG, Y.B.; BUT, P.P.H.; WANG Z.T. Current approaches for the authentication of medicinal Dendrobium species and its products. Plant Genetic Resourchs, v.3 p.144-8, 2005. 